\title{
Implementing interprofessional bedside rounding at the prequalification stage
}

\author{
This article was published in the following Dove Press journal: \\ Journal of Multidisciplinary Healthcare \\ 26 October 2016 \\ Number of times this article has been viewed
}

\author{
Daniel R Tuite' \\ David Healy' \\ Thomas S MacKinnon² \\ 'Faculty of Medicine, Brighton and \\ Sussex Medical School, Brighton, \\ ${ }^{2}$ School of Medicine, Imperial \\ College London, London, UK
}

Correspondence: Daniel Tuite Audrey Emerton Building, Brighton and Sussex Medical School, Eastern Road, Brighton, BN2 OAE, UK

Email D.Tuitel@uni.bsms.ac.uk

\section{Dear editor}

We read with great interest the paper by Henkin et al, ${ }^{1}$ demonstrating that the use of interprofessional bedside rounding (IBR) significantly improved nurse-physician teamwork, particularly from the nurses' point of view. This finding is relevant when one takes into account the importance of interdisciplinary teamwork; a review conducted by Epstein concluded that effective interprofessional teamwork both maximizes patient safety and increases job satisfaction and efficiency. ${ }^{2} \mathrm{We}$, as medical students, believe that inadequate emphasis is placed on interprofessional collaboration at the prequalification phase, and therefore, we suggest that implementing IBR at the university level could represent a method to improve teamwork between the nurses and doctors of the future.

The lack of a significant improvement in Safety Attitudes Questionnaire (SAQ) scores of doctors following IBR implementation in Henkin et al's study suggested that physicians' teamwork benefited less from the exercise than that of nurses. While the reasons for this may be multifactorial, it is possible that this attitudinal disparity relates to hierarchical differences. ${ }^{3}$ We additionally suggest that these discrepancies in baseline attitude may, in part, be due to an "us and them" mindset already ingrained in both parties at the point of qualification.

Leipzig et al demonstrated that senior doctors within a multidisciplinary team were less positively inclined toward interdisciplinary teamwork; ${ }^{4}$ however, there is evidence to suggest that this perception is, in fact, deeply embedded at an earlier stage, with a study indicating that negative perceptions of nurses can exist among medical students as early as their first year of study. ${ }^{5}$ Interestingly, Carpenter has shown that programs which promote early teamwork between different health care professions are successful in diminishing stereotypes. ${ }^{6}$ Therefore, in order to pursue an improvement in interprofessional practice, we believe that it may be preferable to implement interventions such as IBR before qualification. Furthermore, it could be an effective method of encouraging a culture of inclusivity and respect in health care students and, as a result, could optimize the efficacy of the multidisciplinary team.

We acknowledge that integrated teaching does already exist at many UK medical and nursing schools. Yet, from our experience as student doctors, although our "shared learning" sessions were useful in introducing us to nursing students in a classroom context, these were limited at promoting a sense of integration and teamwork within a clinical setting. This is consistent with a report by Horsburgh et al stating that "shared 
learning" may be ineffective, suggesting instead that "interprofessional clinical learning" such as IBR allows students to acquire clinical knowledge and understand the complexities of a multiprofessional environment. ${ }^{7}$

Although in the UK it is a General Medical Council requirement for medical schools to provide opportunities "to work and learn with other health and social care professionals and students to support interprofessional multidisciplinary working", ${ }^{8}$ there is currently no universal framework in place indicating how these opportunities for interprofessional engagement should be delivered. However, Bridges et al identify "didactic, community and clinical teaching" as the core components of medical education, ${ }^{9}$ with IBR representing a clinical method of bringing together nursing and medical students, while providing a true-to-life example of interprofessional practice.

Indeed, there would be challenges to the implementation of student IBR. The educational needs of nursing and medical students differ, and as such, tailoring a teaching ward round to suit both would require consideration. This also poses questions as to which professional would lead the teaching. Furthermore, grouping of students may lead to overcrowding, which may be uncomfortable for patients and inefficient for the progression of the round. A possible solution could involve the creation of supplementary ward rounds for educational purposes.

A pilot study commencing with a small cohort of nursing and medical students would be useful in establishing the feasibility of student IBR. Methodology akin to that of Henkin et al's trial, combined with the use of Parsell and Bligh's Readiness for Interprofessional Learning Survey, ${ }^{1,10}$ could enable measurement of changes in interprofessional teamwork. Also, a survey of patients present would be important to assess their perspective.
In summary, we feel that IBR, at a student level, could represent a beneficial and clinically applicable method to cultivate interdisciplinary collaboration at an early stage. By nurturing and sharing a more cooperative mentality in their early training years, future doctors and nurses are more likely to work "together" rather than "alongside" each other, ultimately resulting in better patient care.

\section{Disclosure}

The authors report no conflicts of interest in this communication.

\section{References}

1. Henkin S, Chon TY, Christopherson ML, Halvorsen AJ, Worden LM, Ratelle JT. Improving nurse-physician teamwork through interprofessional bedside rounding. J Multidiscip Healthc. 2016;9:201-205.

2. Epstein NE. Multidisciplinary in-hospital teams improve patient outcomes: a review. Surg Neurol Int. 2014;5(Suppl 7):S295-S303.

3. Busby A, Gilchrist B. The role of the nurse in the medical ward round. J Adv Nurs. 1992;17(3):339-346.

4. Leipzig RM, Hyer K, Ek K, et al. Attitudes toward working on interdisciplinary healthcare teams: a comparison by discipline. J Am Geriatr Soc. 2002;50(6):1141-1148.

5. Delunas LR, Rouse S. Nursing and medical student attitudes about communication and collaboration before and after an interprofessional education experience. Nurs Educ Perspect. 2014;35(2):100-105.

6. Carpenter J. Interprofessional education for medical and nursing students: evaluation of a programme. Med Educ. 1995;29(4):265-272.

7. Horsburgh M, Lamdin R, Williamson E. Multiprofessional learning: the attitudes of medical, nursing and pharmacy students to shared learning. Med Educ. 2001;35(9):876-883.

8. Promoting excellence: standards for medical education and training. [Internet] General Medical Council; 2016. Available from: http://www. gmc-uk.org/education/27394.asp. Accessed September 2, 2016.

9. Bridges DR, Davidson RA, Soule Odegard P, Maki IV, Tomkowiak J. Interprofessional collaboration: three best practice models of interprofessional education. Med Educ Online. 2011;16:1-10.

10. Parsell G, Bligh J. The development of a questionnaire to assess the readiness of health care students for interprofessional learning (RIPLS). Med Educ. 1999;33(2):95-100. Dove Medical Press encourages responsible, free and frank academic debate. The content of the Journal of Multidisciplinary Healthcare 'letters to the editor' section does not necessarily
represent the views of Dove Medical Press, its officers, agents, employees, related entities or the Journal of Multidisciplinary Healthcare editors. While all reasonable steps have been taken
to confirm the content of each letter, Dove Medical Press accepts no liability in respect of the content of any letter, nor is it responsible for the content and accuracy of any letter to the editor.

\section{Publish your work in this journal}

The Journal of Multidisciplinary Healthcare is an international, peerreviewed open-access journal that aims to represent and publish research in healthcare areas delivered by practitioners of different disciplines. This includes studies and reviews conducted by multidisciplinary teams as well as research which evaluates the results or conduct of such teams or health care processes in general. The journal covers a very wide range of areas and welcomes submissions from practitioners at all levels, from all over the world. The manuscript management system is completely online and includes a very quick and fair peer-review system. Visit http://www.dovepress.com/ testimonials.php to read real quotes from published authors. 